\title{
Allometric models for non-destructive leaf area measurement of stevia: an in depth and complete analysis
}

\author{
Israel A Hernández-Fernandéz ${ }^{1} \mathbb{D}$; Alfredo Jarma-Orozco ${ }^{1} \mathbb{D}$; Marcelo F Pompelli ${ }^{2} \mathbb{D} *$
}

${ }^{1}$ Regional Group of Participatory Research of Small Farmers of the Colombian Atlantic Coast INVEPAR, Faculty of Agricultural Sciences, University of Cordoba, Montería, Córdoba, Colombia; ajarma@correo.unicordoba.edu.co; ${ }^{2}$ Laboratório de Ecofisiologia Vegetal, Departamento de Botânica, Centro de Biociências, Universidade Federal de Pernambuco (UFPE), Recife-PE, Brasil; mfpompelli@gmail. com (*corresponding author)

\begin{abstract}
Leaf area measurement is pivotal for plant physiologists. Hence, accurate measurement of their leaf area is incredibly relevant in agronomic terms. The plant Stevia rebaudiana is a sucrose-free plant species that is now vital to the global production of sucrose-free foods. Here, we estimated $S$. rebaudiana leaf area using a nondestructive methodology comprising allometric equations. Through leaf length (L), leaf width (W), and/or their product (LW) the leaf area was determined. One thousand leaves were sampled from four distinct $S$. rebaudiana genotypes for model construction. Linear or power models were generated, and the best equation was selected using a statistical criterion. The statistical criteria indicated that the linear models best suited all genotypes tested, included a function of LW, exhibited increased stability, and precisely estimated coefficients. ANOVA revealed that both generalized and combined equations were feasible. Nevertheless, grouping all genotypes into a single model was not possible as the genotype leaf architectures were very dissimilar.
\end{abstract}

Keywords: Stevia rebaudiana, general allometric model, leaf area estimation, linear and power models, morphological leaf traits, statistical analysis.

\section{RESUMO}

Modelos alométricos não destrutivos para estimação da área foliar de stevia: uma análise completa e profunda

A medição da área foliar é de extrema importância para os estudos de fisiologia vegetal. Assim, é fundamental a medição precisa de sua área foliar nos estudos agronômicos. Stevia rebaudiana é uma espécie produtora de esteviosídeo, uma substância utilizada como adoçante natural, mundialmente conhecida em produtos sacarosefree. A área foliar de $S$. rebaudiana foi estimada por metodologia não destrutiva compreendendo equações alométricas que foram determinadas através do comprimento da folha (L), largura da folha (W) e / ou seu produto (LW). Foram amostradas mil folhas de quatro genótipos distintos de $S$. rebaudiana para construção do modelo. Modelos lineares e não lineares foram gerados e a melhor equação foi selecionada usando-se critérios estatísticos robustos, os quais indicaram que os modelos lineares se adequavam melhor a todos os genótipos testados, exibiam maior estabilidade e precisos coeficientes estimados. AANOVA revelou que a equação generalizada é viável; no entanto, o agrupamento de todos os genótipos em um único modelo é contraindicado, pois as arquiteturas genotípicas das folhas são muito distintas.

Palavras-chave: Stevia rebaudiana, modelo alométrico geral, alometria foliar, modelos lineares e potenciais, características morfológicas foliares, análises estatísticas, plantas livres de açúcares.

Received on September 18, 2020; accepted on April 21, 2021

$S$ tevia rebaudiana is a small perennial plant, reaching a height of $65-80$ $\mathrm{cm}$. Various stevia species contain sweetening compounds, such as diterpene glycosides but $S$. rebaudiana has the highest concentrations of these substances, whose are of considerable interest for sucrose-free food production. Stevia plants contain steviol glycosides, that are $\sim 300$ times sweeter than sucrose at $0.4 \%(\mathrm{w} / \mathrm{v})$ (Kinghorn \& Soejarto, 1991). The incidences of cardiovascular diseases, diabetes, hypercholesterolemia, and obesity have increased globally (Guerrero et al., 2018). Consequently, the demand for non-caloric sweeteners has increased and sugar consumption has decreased (Putnik et al., 2020). In addition to being natural sweeteners, stevia leaf lowers blood pressure, improves gastrointestinal function, and protects against dental caries (Kinghorn \& Soejarto, 1991). The growing worldwide demand for natural sweeteners has induced large-scale $S$. rebaudiana cultivation.

Humankind has learned to cultivate various plant species. The leaves of horticultural plants, such as lettuce, watercress, celery, chard, and spinach may be directly consumed. Other horticultural plants such as basil, marjoram, parsley, coriander, onion, and bay leaf are cultivated for condiments and food preservation. Still other horticultural plants such as lemongrass, chamomile, lemon, orange, eucalyptus, and stevia leaves can be consumed as 
such, see e.g., their use in Paraguay and other countries where they are used as tea or for sweetening purposes but are sources of commercially important compounds. Hence, in the leaves of these species are the main organs of commercial interest. For this reason, a major agroeconomic objective in the cultivation of these plants is to maximize their leaf area (LA). The leaf is the main photosynthetic organ for most plants. Thus, accurate LA determination is vital to the production of these crops (Antunes et al., 2008; Pompelli et al., 2012). It is not possible to confirm that greater amounts of sweetening compounds are directly proportional to the leaf development. However, it is quite plausible to argue that plants with a larger leaf area are more likely to produce a greater amount of sweeteners, since the synthesis of sweeteners starts in the stroma of the chloroplasts (Totté et al., 2000; Ceunen \& Geuns, $2013 \mathrm{c}$ ). Larger leaf area denotes more chloroplasts and consequently more sweeteners can be produced. Notwithstanding, LA measurement is critical in ecophysiological, agricultural, and ecological research (Pandey, 2011). LA has been widely used to describe growth, productivity, photosynthetic efficiency, soil salinity and acidity, heat transfer, carbon, nutrients, and water exchange into the atmosphere. In turn, these properties influence crop yield (Antunes et al., 2008; Pompelli et al., 2012, 2019).

The direct measurement of individual LA is both, laborious, expensive, time-consuming, and constrained by logistical factors. A modeling approach is crucial for the evaluation of continuous changes in LA and growth (Pompelli et al., 2012). Accurate LA estimation is required to understand and model ecosystem function (Antunes $e t$ al., 2008). New tools and machines, such as hand scanners and laser optic apparatuses, and more recently (Adhikari et al., 2020), low-cost smartphone software have been developed for LA measurements. However, some of them are too expensive and complex for basic and simple studies (Demirsoy, 2009). Allometry establishes quantitative relationships among characteristic dimensions such as LA, and volume that are not readily determined directly. Allometric models estimate the leaf area in a non-destructive way and are useful in horticultural experiments. In addition, they enable LA measurements of the same leaf throughout the growth period and may, therefore, reduce data variability (Antunes et al., 2008; Pompelli et al., 2012, 2019). The use of simple linear measurements to predict LA for horticultural plants eliminates the need for costly LA meters (Antunes et al., 2008; Pandey, 2011; Pompelli et al., 2012;Adhikari et al., 2020). Modeling the linear relationships among LA and other leaf dimensions rapidly, reliably, inexpensively, accurately and nondestructively measure LA (Antunes et al., 2008; Pompelli et al., 2012; Adhikari et al., 2020). The development of statistical regression models from linear leaf measurements to predict total and individual LA has been useful for growth and development studies (Achten et al., 2010; Adhikari et al., 2020). Thus, simple linear measurements, such as leaf length (L) and leaf width (W) are used in allometric equations to model the observed LA (Achten et al., 2010). Nondestructive allometry for LA determination has been a subject of intensive research, particularly for plants of high economic value, such as grapevine (Teobaldelli et al., 2020), purging nut (Achten et al., 2010; Pompelli et al., 2012), among others.

In numerous studies, however, the adequacy of the model assumptions for LA estimation has not been critically assessed. Even minor violations of the underlying assumptions could invalidate the inferences drawn from the analysis (Chatterjee \& Hadi, 2006). Two prior studies described allometric models to estimate $S$. rebaudiana LA. Ramesh et al. (2007) used only 80-300 leaves to construct their allometric models, and Lima Filho \& Malavolta (1986) applied only 70 leaves for that purpose. The major flaw in both models was the lack of regression coefficients $\left(b_{n}\right)$, stability testing and, by extension, model validation. Furthermore, the studies did not conduct morphological analyses of the $S$. rebaudiana leaves. This error was serious as $S$. rebaudiana presents distinct and widely varied leaf morphotypes (Hastoy et al., 2019). Here, then, we propose the following hypotheses: $(i)$ the current allometric equations for estimating $S$. rebaudiana LA are unbiased; (ii) the linear models are reliable for estimating $S$. rebaudiana LA; (iii) a generalized equation for estimating $S$. rebaudiana LA is feasible; and (iv) leaf length is the factor that contributes the most in the variation to the LA in various genetic materials.

\section{MATERIAL AND METHODS}

\section{Plant material and environmental conditions}

Four Stevia rebaudiana genotypes were studied: a commercial (Morita II) and three experimental (clones 4, 16, and 18), which were obtained by natural pollination in a controlled greenhouse after selection among 25 distinct started genotypes (Aramendiz-Tatis et al., 2021). The $S$. rebaudiana leaves were collected from the experimental campus of the Facultad de Ciencias Agrícolas of Universidad de Córdoba ( $8^{\circ} 47^{\prime} 37^{\prime}$ 'N, $75^{\circ} 51^{\prime} 51^{\prime \prime} \mathrm{W}, 15 \mathrm{~m}$ altitude). The region has a mean annual rainfall of 1,346 $\mathrm{mm}$, a relative humidity of $84 \%$, and a mean annual temperature of $27.4^{\circ} \mathrm{C}$. It is characterized by a tropical wet climate according to the Köppen's climate classification system.

\section{Plant samples and processing}

The $S$. rebaudiana individuals selected for leaf collection belonged to various age classes assuming to have wide genetic variability. One thousand healthy developing and mature leaves were harvested per genotype. The leaves were randomly sampled from various parts of the plants and measured to develop the best fitting model for predicting $S$. rebaudiana LA. The leaves were scanned at 1,200 dpi × 1,200 dpi resolution using the HP PSC1410 (HP Corp., Palo Alto, CA, USA), and the images were analyzed with ImagePro ${ }^{\circledR}$ Plus (v. 4.5.0.29; Media Cybernetics, Silver Spring, MD, USA) as described in detail by Pompelli et al. (2012). The leaf samples covered the broadest possible dimensional ranges (Table 1). 
Several linear and nonlinear regression models using width (W) and/ or length (L) were developed for each plant genotype. The following statistical criteria were used in model selection: $(i)$ F-test, (ii) sample-adjusted coefficients of determination, (iii) stability and standard errors of estimates, and (iv) residual dispersion patterns. The data exploration protocol of Zuur et al. (2009) was used to verify statistical assumptions such as normality and independence of errors. The DurbinWatson criteria (Durbin \& Watson, 1950) were applied to select accurate, parsimonious equations. In this manner, model bias, precision, simplicity, and accuracy could be evaluated (Walther $\&$ Moore, 2005).

\section{Model validation}

Five hundred leaves of different genotypes were sampled from various $S$. rebaudiana plants grown under the same conditions as those used for model construction. Previously selected models were re-estimated using new validation samples, and the data were compared by calibrating models. The estimated leaf areas (ELA) obtained with the models were plotted against the measured leaf areas (MLA) and linear regression curves were plotted.

\section{Model identity test}

To assess whether a given model could accurately estimate LA for all genotypes with distinct leaf morphology, the following statistical null hypothesis was set up: $\mathrm{H}_{0}: \beta_{1}=\beta_{2}=\beta_{\mathrm{n}}$, where $\beta_{1}$, $\beta_{2}$, and $\beta_{\mathrm{n}}$ are regression coefficients. The null hypothesis postulated that there were no differences among coefficients based on the differences between the sums of squares of the complete model. Rejection of $\mathrm{H}_{0}$ implied evidence for the acceptance of the alternative hypothesis, namely, significant differences among models for all genotypes.

\section{Principal component analysis}

The morphological parameters were used to run a principal component analysis (PCA) in the PCA function of Minitab v. 18.1.0.0 (Minitab LLC, Pennsylvania State University, University Park, PA, USA). The PCA summary function calculated the proportion of variance in each morphological parameter explained by each principal component axis. For hierarchical clustering, Pearson's correlations were used to compare similarities among genotypes via the "cor" function in R (R Core Team, Murray Hill, NJ, USA). The complete linkage method and the Euclidean distance were used for hierarchical clustering with the $\mathrm{R}$ index in Minitab.

\section{Statistical data analysis}

Statistical analyses were performed in Statistica v. 8.0 (StatSoft, Tulsa, OK, USA), DataFit v. 8.0.32 (Oakdale Engineering, Oakdale, PA, USA), SigmaPlot for Windows v. 11.0 (Systat Software, Inc., San Jose, CA, USA) and R v. 3.3.3 (CoreTeam, 2020). All other calculations, statistical analyses, and graph generation were performed in GerminaR (Lozano-Isla et al., 2020). To identify significant differences among factors the ANOVA was performed. With a Student-Newman-Keuls test the means were compared. $P<0.001$ was considered statistically significant.

\section{RESULTS AND DISCUSSION}

The large sample size used in this study $(n=1,000)$ revealed a diversity of leaf size ranging from expanding to fully expanded leaves. The leaf length ranges were $1.74-5.49 \mathrm{~cm}$ (genotype 4), 2.56-6.40 cm (genotype 16), 2.27-6.07 $\mathrm{cm}$ (genotype 18), and $2.37-7.03 \mathrm{~cm}$ (Morita II). The leaf width ranges were 0.95-2.59 cm, 0.98-3.27 cm, 1.10-2.88 $\mathrm{cm}$, and $1.01-2.81 \mathrm{~cm}$ for the same respective genotypes. Thus, the average LA were $3.77 \pm 1.10 \mathrm{~cm}^{2}, 4.41 \pm 1.24$ $\mathrm{cm}^{2}, 5.71 \pm 1.54 \mathrm{~cm}^{2}$, and $6.29 \pm 1.62 \mathrm{~cm}^{2}$ for genotypes 4, 18, Morita, and 16, respectively (Table 1). Several studies (Antunes et al., 2008; Pompelli et al., 2012) reported that using small sample sizes to construct leaf area allometric models can generate biased equations. A few studies used only expanded leaves (Lima Filho \& Malavolta, 1986; Ramesh et al., 2007; Achten et al., 2010). However, this practice is not recommended for the construction of allometric models because agricultural treatments must be applied to whole plants and not merely the leaves alone. Hence, certain size selection criteria must be met, and the management and interpretation of horticultural characteristics become difficult. Pompelli et al. (2012) compared the methods of Achten et al. (2010) against a standard LA measurement method and found that the former were biased and substantially underestimated LA. For this reason, we were unsuccessful at validating the allometric equations proposed by Ramesh et al. (2007) and Lima Filho \& Malavolta (1986). Nevertheless, these equations were selected only based on their coefficients of determination $\left(\mathrm{R}^{2}\right)$ and their standard errors of the estimate. The accuracy of those equations was not tested.

At least 125 equations were generated per genotype. Of these, at least 36 exhibited satisfactory biological behavior. To reduce complexity, we

Table 1. Means \pm standard deviations (SD), minimum (Min) and maximum (Max) values for the leaf length and width and leaf area of 1,000 independent Stevia rebaudiana leaves. Cordoba, University of Cordoba, 2020.

\begin{tabular}{|c|c|c|c|c|c|c|c|c|c|}
\hline \multirow{2}{*}{ Genotypes } & \multicolumn{3}{|c|}{ Leaf length $(\mathrm{cm})$} & \multicolumn{3}{|c|}{ Leaf width (cm) } & \multicolumn{3}{|c|}{ Leaf area $\left(\mathrm{cm}^{2}\right)$} \\
\hline & $\overline{\mathbf{x}}$ & Min & Max & $\overline{\mathbf{x}}$ & Min & Max & $\overline{\mathbf{x}}$ & Min & Max \\
\hline 4 & $3.18 \pm 0.52$ & 1.74 & 5.49 & $1.64 \pm 0.28$ & 0.95 & 2.59 & $3.77 \pm 1.10$ & 1.34 & 8.06 \\
\hline 16 & $3.94 \pm 0.52$ & 2.56 & 6.40 & $2.29 \pm 0.36$ & 0.98 & 3.27 & $6.29 \pm 1.62$ & 1.96 & 12.15 \\
\hline 18 & $3.72 \pm 0.60$ & 2.27 & 6.07 & $1.84 \pm 0.27$ & 1.10 & 2.88 & $4.41 \pm 1.24$ & 1.83 & 10.13 \\
\hline Morita II & $4.54 \pm 0.80$ & 2.37 & 7.03 & $1.88 \pm 0.28$ & 1.01 & 2.81 & $5.71 \pm 1.54$ & 1.92 & 11.23 \\
\hline
\end{tabular}


disqualified second- to sixth-order exponential, logarithmic, and polynomial equations. Therefore, we presented only nine main equations including those that were linear with a zero intercept, linear with non-zero intercept, and power models. All of them were generated from linear measurements of $\mathrm{L}, \mathrm{W}$, or both (Table 2). The coefficients of

Table 2. Statistical models, regression coefficients $\left(\beta_{0}\right.$ and $\left.\beta_{1}\right)$, standard errors of estimates (SE), coefficients of determination adjusted for the degrees of freedom $\left(\mathrm{R}_{\mathrm{a}}{ }^{2}\right)$, mean square error $\left(\mathrm{MS}_{\mathrm{es}}\right)$, calculated $\mathrm{F}\left(\mathrm{F}_{\text {calc }}\right)$, $\mathrm{P}$ value, and equations of leaf area as a function of linear dimensions of leaves (length, L, and width, W) of Stevia rebaudiana leaves. Cordoba, University of Cordoba, 2020.

\begin{tabular}{|c|c|c|c|c|c|c|c|c|c|}
\hline \multirow{2}{*}{$\begin{array}{l}\text { Equation } \\
\text { Number }\end{array}$} & \multirow{2}{*}{ Model } & \multicolumn{2}{|c|}{ Coefficients } & \multirow{2}{*}{ SE } & \multirow{2}{*}{$\mathbf{R}_{\mathrm{a}}^{2}$} & \multirow{2}{*}{$\mathbf{M S}_{\text {res }}$} & \multirow{2}{*}{$\mathbf{F}_{\text {calc }}$} & \multirow{2}{*}{$\mathbf{P}$} & \multirow{2}{*}{ Estimator of LA $(\hat{Y})^{*}$} \\
\hline & & $\beta_{0}$ & $\beta_{1}$ & & & & & & \\
\hline \multicolumn{10}{|c|}{ Genotype 04} \\
\hline$\# 1$ & $\mathrm{Y}=\beta_{1}^{*} \mathrm{~W}+\varepsilon_{\mathrm{i}}$ & -- & 2.3337 & 0.5652 & 0.9783 & 0.3194 & $47,369.91$ & $<0.0001$ & $\hat{\mathrm{Y}}=2.3337 *(\mathrm{~W})$ \\
\hline$\# 2$ & $\mathrm{Y}=\beta_{0}+\beta_{1}^{*} \mathrm{~W}+\varepsilon_{\mathrm{i}}$ & -2.2004 & 3.6349 & 0.4278 & 0.8498 & 0.1830 & $5,654.56$ & $<0.0001$ & $\hat{\mathrm{Y}}=-2.2004+3.6349 *(\mathrm{~W})$ \\
\hline$\# 3$ & $\mathrm{Y}=\beta_{0} * \mathrm{~W}^{\beta 1}+\varepsilon_{\mathrm{i}}$ & 1.6931 & 1.5861 & 0.4216 & 0.8541 & 0.1777 & $5,850.84$ & $<0.0001$ & $\hat{\mathrm{Y}}=1.6931 *(\mathrm{~W})^{1.5861}$ \\
\hline$\# 4$ & $\mathrm{Y}=\beta_{1}^{*} \mathrm{~L}+\varepsilon_{\mathrm{i}}$ & --- & 1.200 & 0.6770 & 0.9694 & 0.4583 & $32,714.97$ & $<0.0001$ & $\hat{\mathrm{Y}}=1.5861 *(\mathrm{~L})$ \\
\hline$\# 5$ & $\mathrm{Y}=\beta_{0}+\beta_{1} * \mathrm{~L}+\varepsilon_{\mathrm{i}}$ & -1.9275 & 1.7903 & 0.6028 & 0.7019 & 0.3633 & $2,353.08$ & $<0.0001$ & $\hat{\mathrm{Y}}=-1.9275+1.7903 *(\mathrm{~L})$ \\
\hline \#6 & $\mathrm{Y}=\beta_{0} * \mathrm{~L}^{\beta_{1}}+\varepsilon_{\mathrm{i}}$ & 0.6640 & 1.4921 & 0.6024 & 0.7022 & 0.3629 & $2,357.02$ & $<0.0001$ & $\hat{\mathrm{Y}}=0.6640 *(\mathrm{~L})^{1.4921}$ \\
\hline$\# 7$ & $\mathrm{Y}=\beta_{1}^{*} \mathrm{LW}+\varepsilon_{\mathrm{i}}$ & --- & 0.7041 & 0.2742 & 0.9941 & 0.0752 & $204,489.09$ & $<0.0001$ & $\hat{\mathrm{Y}}=0.7041^{*}(\mathrm{LW})$ \\
\hline$\# 8$ & $\mathrm{Y}=\beta_{0}+\beta_{1}{ }^{*} \mathrm{LW}+\varepsilon_{\mathrm{i}}$ & 0.2629 & 0.6590 & 0.2634 & 0.9431 & 0.0694 & $16,555.51$ & $<0.0001$ & $\hat{\mathrm{Y}}=0.2629+0.6590 *(\mathrm{LW})$ \\
\hline$\# 9$ & $\mathrm{Y}=\beta_{0} * \mathrm{LW}^{\beta 1}+\varepsilon_{\mathrm{i}}$ & 0.7996 & 0.9295 & 0.2619 & 0.9437 & 0.0686 & $16,753.86$ & $<0.0001$ & $\hat{\mathrm{Y}}=0.7996 *(\mathrm{LW})^{0.9295}$ \\
\hline \multicolumn{10}{|c|}{ Genotype 16} \\
\hline$\# 1$ & $\mathrm{Y}=\beta_{1}^{*} \mathrm{~W}+\varepsilon_{\mathrm{i}}$ & -- & 2.7849 & 0.7880 & 0.9843 & 0.6209 & $67,055.07$ & $<0.0001$ & $\hat{\mathrm{Y}}=2.7849 *(\mathrm{~W})$ \\
\hline$\# 2$ & $\mathrm{Y}=\beta_{0}+\beta_{1}^{*} \mathrm{~W}+\varepsilon_{\mathrm{i}}$ & -3.2219 & 4.1584 & 0.6061 & 0.8606 & 0.3673 & $6,177.70$ & $<0.0001$ & $\hat{\mathrm{Y}}=-3.2219+4.1584 *(\mathrm{~W})$ \\
\hline$\# 3$ & $\mathrm{Y}=\beta_{0}^{*} \mathrm{~W}^{\beta 1}+\varepsilon_{\mathrm{i}}$ & 1.6398 & 1.6086 & 0.5714 & 0.8762 & 0.3265 & $7,073.60$ & $<0.0001$ & $\hat{\mathrm{Y}}=1.6398^{*}(\mathrm{~W})^{1.6086}$ \\
\hline$\# 4$ & $\mathrm{Y}=\beta_{1}^{*} \mathrm{~L}+\varepsilon_{\mathrm{i}}$ & --- & 1.6151 & 1.0396 & 0.9734 & 1.0808 & $38,099.16$ & $<0.0001$ & $\hat{\mathrm{Y}}=1.6151 *(\mathrm{~L})$ \\
\hline$\# 5$ & $\mathrm{Y}=\beta_{0}+\beta_{1} * \mathrm{~L}+\varepsilon_{\mathrm{i}}$ & -4.0469 & 2.6251 & 0.8975 & 0.6947 & 0.8055 & $2,274.01$ & $<0.0001$ & $\hat{\mathrm{Y}}=-4.0469+2.6251 *(\mathrm{~L})$ \\
\hline \#6 & $\mathrm{Y}=\beta_{0} * \mathrm{~L}^{\beta 1}+\varepsilon_{\mathrm{i}}$ & 0.6748 & 1.6228 & 0.9025 & 0.6913 & 0.8145 & $2,237.70$ & $<0.0001$ & $\hat{\mathrm{Y}}=0.6748 *(\mathrm{~L})^{1.6228}$ \\
\hline$\# 7$ & $\mathrm{Y}=\beta_{1}^{*} \mathrm{LW}+\varepsilon_{\mathrm{i}}$ & --- & 0.6879 & 0.3267 & 0.9965 & 0.1067 & $394,912.94$ & $<0.0001$ & $\hat{\mathrm{Y}}=0.6879 *(\mathrm{LW})$ \\
\hline$\# 8$ & $\mathrm{Y}=\beta_{0}+\beta_{1}^{*} \mathrm{LW}+\varepsilon_{\mathrm{i}}$ & 0.1608 & 0.6715 & 0.3244 & 0.9601 & 0.1052 & $24,054.20$ & $<0.0001$ & $\hat{\mathrm{Y}}=0.1608+0.6715 *(\mathrm{LW})$ \\
\hline$\# 9$ & $\mathrm{Y}=\beta_{0} * \mathrm{LW}^{\beta 1}+\varepsilon_{\mathrm{i}}$ & 0.7344 & 0.9717 & 0.3239 & 0.9602 & 0.1049 & $24,131.71$ & $<0.0001$ & $\hat{\mathrm{Y}}=0.7344 *(\mathrm{LW})^{0.9717}$ \\
\hline \multicolumn{10}{|c|}{ Genotype 18} \\
\hline$\# 1$ & $\mathrm{Y}=\beta_{1}^{*} \mathrm{~W}+\varepsilon_{\mathrm{i}}$ & --- & 2.4423 & 0.6737 & 0.9774 & 0.4539 & $45,186.89$ & $<0.0001$ & $\hat{\mathrm{Y}}=2.4423 *(\mathrm{~W})$ \\
\hline$\# 2$ & $\mathrm{Y}=\beta_{0}+\beta_{1} * \mathrm{~W}+\varepsilon_{\mathrm{i}}$ & -3.6120 & 4.3701 & 0.4306 & 0.8794 & 0.1854 & $7,286.99$ & $<0.0001$ & $\hat{\mathrm{Y}}=-3.6120+4.3701 *(\mathrm{~W})$ \\
\hline$\# 3$ & $\mathrm{Y}=\beta_{0} * \mathrm{~W}^{\beta 1}+\varepsilon_{\mathrm{i}}$ & 1.4446 & 1.8115 & 0.4103 & 0.8905 & 0.1683 & $8,127.39$ & $<0.0001$ & $\hat{\mathrm{Y}}=1.4446^{*}(\mathrm{~W})^{1.8115}$ \\
\hline$\# 4$ & $\mathrm{Y}=\beta_{1}^{*} \mathrm{~L}+\varepsilon_{\mathrm{i}}$ & --- & 1.2014 & 0.6871 & 0.9765 & 0.4721 & $43,406.05$ & $<0.0001$ & $\hat{\mathrm{Y}}=1.2014 *(\mathrm{~L})$ \\
\hline$\# 5$ & $\mathrm{Y}=\beta_{0}+\beta_{1}^{*} \mathrm{~L}+\varepsilon_{\mathrm{i}}$ & -2.4716 & 1.8491 & 0.5648 & 0.7925 & 0.3190 & $3,816.62$ & $<0.0001$ & $\hat{\mathrm{Y}}=-2.4716+1.8491 *(\mathrm{~L})$ \\
\hline$\# 6$ & $\mathrm{Y}=\beta_{0} * \mathrm{~L}^{\beta 1}+\varepsilon_{\mathrm{i}}$ & 0.5789 & 1.5371 & 0.5598 & 0.7962 & 0.3134 & $3,903.05$ & $<0.0001$ & $\hat{\mathrm{Y}}=0.5789 *(\mathrm{~L})^{1.5371}$ \\
\hline$\# 7$ & $\mathrm{Y}=\beta_{1}^{*} \mathrm{LW}+\varepsilon_{\mathrm{i}}$ & --- & 0.6310 & 0.2744 & 0.9954 & 0.0753 & $277,489.22$ & $<0.0001$ & $\hat{\mathrm{Y}}=0.6310^{*}(\mathrm{LW})$ \\
\hline$\# 8$ & $\mathrm{Y}=\beta_{0}+\beta_{1} * \mathrm{LW}+\varepsilon_{\mathrm{i}}$ & 0.2957 & 0.5919 & 0.2614 & 0.9555 & 0.0683 & $21,474.14$ & $<0.0001$ & $\hat{\mathrm{Y}}=0.2957+0.5919^{*}(\mathrm{LW})$ \\
\hline$\# 9$ & $\mathrm{Y}=\beta_{0} * \mathrm{LW}^{\beta 1}+\varepsilon_{\mathrm{i}}$ & 0.7177 & 0.9375 & 0.2612 & 0.9556 & 0.0682 & $21,512.56$ & $<0.0001$ & $\hat{\mathrm{Y}}=0.7344 *(\mathrm{LW})^{0.9717}$ \\
\hline \multicolumn{10}{|c|}{ Genotype Morita II } \\
\hline$\# 1$ & $\mathrm{Y}=\beta_{1}^{*} \mathrm{~W}+\varepsilon_{\mathrm{i}}$ & --- & 3.0836 & 0.8454 & 0.9786 & 0.7147 & $47,893.19$ & $<0.0001$ & $\hat{\mathrm{Y}}=3.0836^{*}(\mathrm{~W})$ \\
\hline$\# 2$ & $\mathrm{Y}=\beta_{0}+\beta_{1}^{*} \mathrm{~W}+\varepsilon_{\mathrm{i}}$ & -3.5863 & 4.9530 & 0.6582 & 0.8171 & 0.4332 & $4,463.98$ & $<0.0001$ & $\hat{\mathrm{Y}}=-3.5863+4.9530 *(\mathrm{~W})$ \\
\hline$\# 3$ & $\mathrm{Y}=\beta_{0} * \mathrm{~W}^{\beta 1}+\varepsilon_{\mathrm{i}}$ & 1.9863 & 1.6575 & 0.6479 & 0.8228 & 0.4197 & $4,639.20$ & $<0.0001$ & $\hat{\mathrm{Y}}=1.9863 *(\mathrm{~W})^{1.6575}$ \\
\hline$\# 4$ & $\mathrm{Y}=\beta_{1}^{*} \mathrm{~L}+\varepsilon_{\mathrm{i}}$ & --- & 1.2661 & 0.9249 & 0.9745 & 0.8554 & $39,853.34$ & $<0.0001$ & $\hat{\mathrm{Y}}=1.2661 *(\mathrm{~L})$ \\
\hline$\# 5$ & $\mathrm{Y}=\beta_{0}+\beta_{1} * \mathrm{~L}+\varepsilon_{\mathrm{i}}$ & -1.3778 & 1.5604 & 0.8936 & 0.6628 & 0.7986 & $1,965.07$ & $<0.0001$ & $\hat{\mathrm{Y}}=-1.3778+1.5604 *(\mathrm{~L})$ \\
\hline \#6 & $\mathrm{Y}=\beta_{0} * \mathrm{~L}^{\beta 1}+\varepsilon_{\mathrm{i}}$ & 0.8607 & 1.2472 & 0.8935 & 0.6629 & 0.7983 & $1,965.92$ & $<0.0001$ & $\hat{\mathrm{Y}}=0.8607 *(\mathrm{~L})^{1.2472}$ \\
\hline$\# 7$ & $\mathrm{Y}=\beta_{1}^{*} \mathrm{LW}+\varepsilon_{\mathrm{i}}$ & -- & 0.6538 & 0.4861 & 0.9922 & 0.2363 & $146,893.27$ & $<0.0001$ & $\hat{\mathrm{Y}}=0.6538 *(\mathrm{LW})$ \\
\hline$\# 8$ & $\mathrm{Y}=\beta_{0}+\beta_{1} * \mathrm{LW}+\varepsilon_{\mathrm{i}}$ & 0.6246 & 0.5872 & 0.4543 & 0.9129 & 0.2064 & $10,468.67$ & $<0.0001$ & $\hat{\mathrm{Y}}=0.6246+0.5872 *(\mathrm{LW})$ \\
\hline$\# 9$ & $\mathrm{Y}=\beta_{0} * \mathrm{LW}^{\beta 1}+\varepsilon_{\mathrm{i}}$ & 0.8458 & 0.8866 & 0.4517 & 0.9138 & 0.2041 & $10,597.18$ & $<0.0001$ & $\hat{\mathrm{Y}}=0.7344 *(\mathrm{LW})^{0.9717}$ \\
\hline
\end{tabular}


determination adjusted for degrees of freedom $\left(\mathrm{R}_{\mathrm{a}}^{2}\right)$ were in the ranges of 0.7019-0.9941 (genotype 4), 0.69130.9965 (genotype 16), 0.7925-0.9954 (genotype 18), and 0.6628-0.9922 (Morita II) (Table 2). Models \#1 and \#7 did not efficiently estimate LA for any of the tested genotypes, as they generated extremely high calculated $\mathrm{F}$ $\left(\mathrm{F}_{\text {calc }}\right)$ values $(\leq 394,912.94)$ for the LA estimation of genotype 16 (equation \#7). Figure 1 shows that equation \#2 was ineffective at estimating any genotype here. Model \#1 slightly overestimated LA, whereas model \#2 strongly overestimated it. Equation \#7 significantly underestimated the LA for all genotypes, except 16. Equation \#4 significantly overestimated the LA for genotype 18 . The first selection disqualified equations \#1, \#2, and \#7 from validation but did not permit the exclusion of equation $\# 4$, as only the LA of genotype 18 was overestimated by $\sim 38 \%$.

Hence, only equations \#3, \#4, \#5, \#6,
$\# 8$, and \#9 remained in the validation process (Figure 2). Allometric LA estimation was perfectly suited to all genotypes, and the variation was

Table 3. Variance analysis for linear models $\left(\mathrm{Y}=\beta_{0}+\beta_{1} \mathrm{X}\right)$, where $\mathrm{X}$ is LW product, using the set of leaves adjustment of the four distinct Stevia rebaudiana leaves: Clone 4, Clone 16, Clone 18, and Clone Morita II $(\mathrm{n}=4,000)$. The dependent and independent variables were log-transformed for the analysis, following recommendations for statistical standardization of the data for variance reduction in accord of Zuur et al. (2009). Cordoba, University of Cordoba, 2020.

\begin{tabular}{lcccc}
\hline Variation font & $\begin{array}{c}\text { Degrees of } \\
\text { Freedon }\end{array}$ & $\begin{array}{c}\text { Sum of } \\
\text { squares }\end{array}$ & $\begin{array}{c}\text { Mean } \\
\text { square }\end{array}$ & $\mathbf{F}_{\text {calc }}$ \\
\hline Parameters & 10 & $2,424.622$ & - & \\
Reduction $(\beta \mathrm{s})$ & 2 & $1,976.070$ & - & \\
Reduction $\left(\mathrm{H}_{0}\right)$ & 8 & 448.552 & 56.069 & $12.736^{*}$ \\
Residual & 3,989 & $17,560.854$ & 4.402 & \\
Total & 3,999 & $19,985.477$ & & \\
\hline
\end{tabular}

$* \mathrm{~F}_{0.01}(8 ; 3,939)=2.516$.

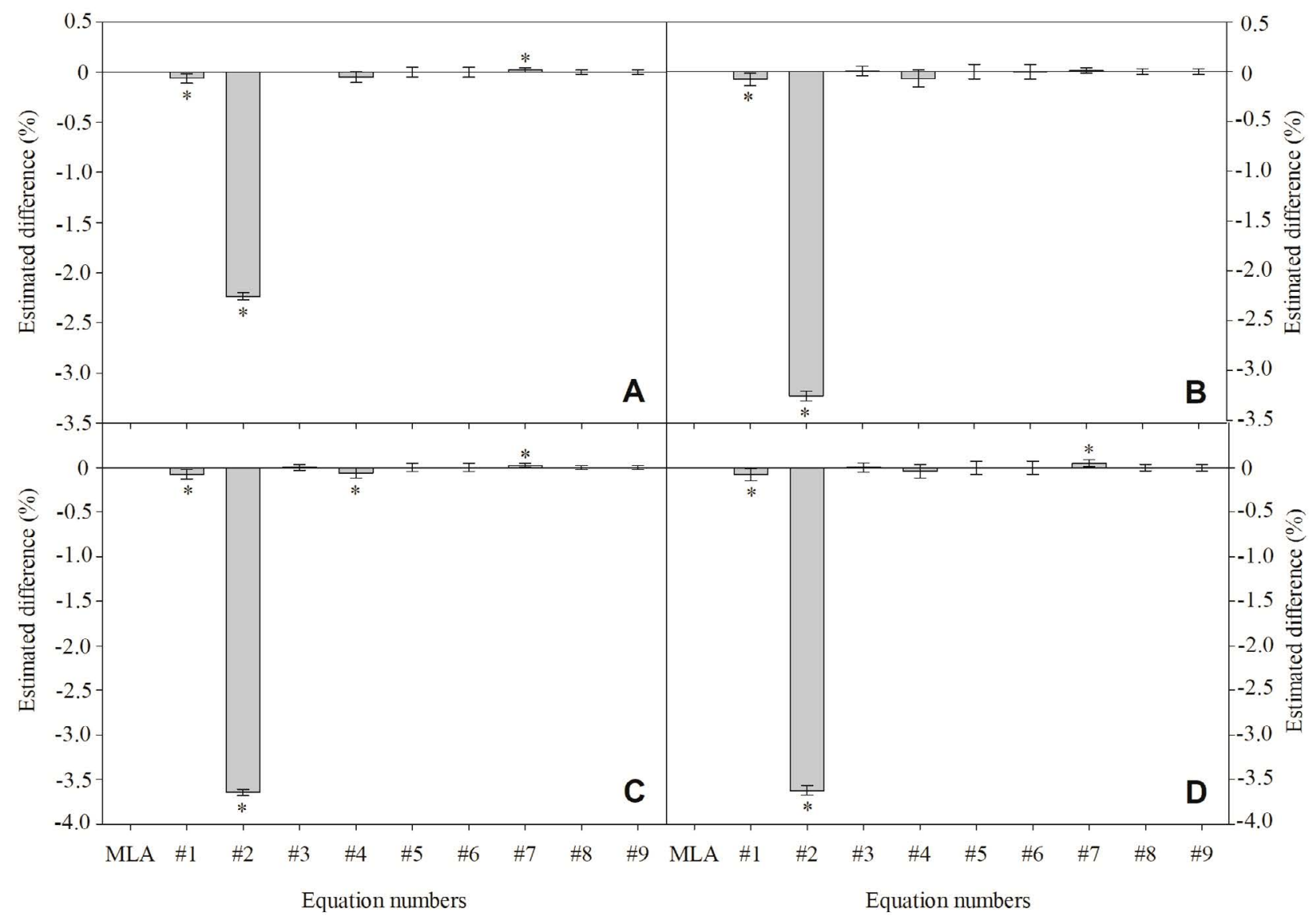

Figure 1. Deviation of the estimated area from the observed leaf area (LAo) for individual leaves. Leaf areas for the genotype 4 (A), 16 (B), 18 (C), and Morita II (D) of Stevia rebaudiana were estimated using several models in which $\beta_{0}$ and $\beta_{1}$ are coefficients. Vertical bars denote means and spreads denote $99 \%$ confidence intervals of the difference (distribution of t-test). For details of the equations and its equation number, see Table 2. The asterisks (*) denotes biased equations. Cordoba, University of Cordoba, 2020. 
not genotype-dependent. However, analysis of the residual dispersion patterns showed that model \#3 slightly overestimated the LA of the Morita II by $\sim 1.1 \%$ (Figure $2 \mathrm{~A}$ ). Nevertheless, this error was insignificant relative to a sample size of 1,000 leaves. Therefore, equation \#3 remained in the
S. rebaudiana LA estimation analysis. In contrast, analysis of the residual dispersion pattern for equation \#4 disclosed a slight overestimation of LA
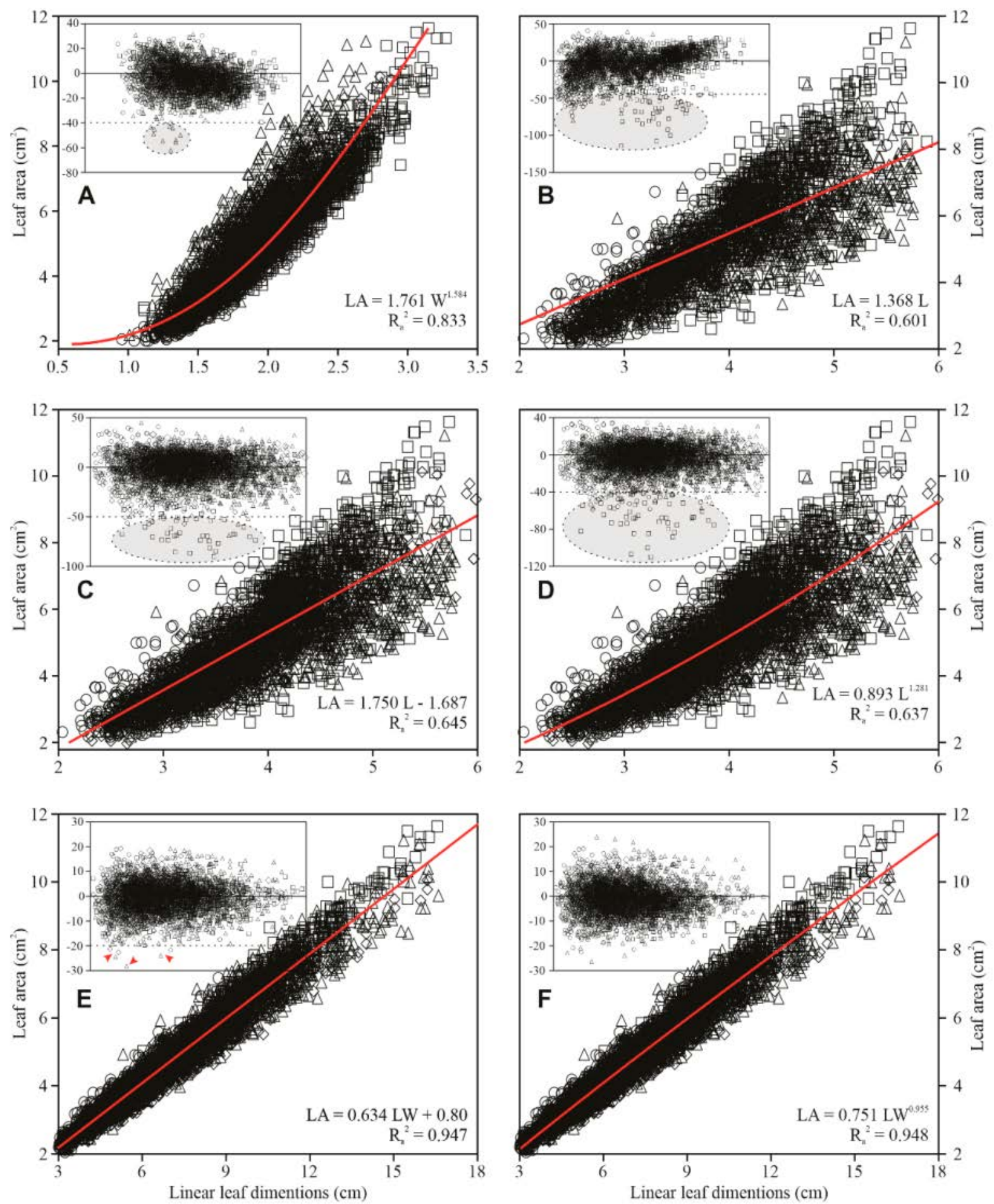

Figure 2. Regression curves for leaf area and linear leaf dimensions: width (A; equation \#3), length (B-D; equation \#4, \#5, and \#6), and product of leaf width and leaf length (E-F; equations \#8, and \#9) for Stevia rebaudiana leaves: Genotypes 4 (circles), 16 (squares), 18 (diamond), and Morita II (triangle), using linear (B, C, and E) and power (A, D, and F) models. The dispersion pattern of residuals for the respective models is shown in the insets. The shaded area denotes the region of highly biased data in the equations causing an overestimation of Stevia rebaudiana leaves, while data pointed with arrows denote a slight overestimation of Stevia rebaudiana leaves. All graphs were generated with 1,000 independent leaves of each Stevia rebaudiana genotypes. Cordoba, University of Cordoba, 2020. 
(4.4\%) for genotype 16 (Figure 2B), especially for the more expanded leaves, as well as LA overestimations of $\sim 1.3 \%$ and $\sim 2.1 \%$ for Morita II and genotype 4 , respectively. With $75 \%$ LA significant overestimation, we considered model 4 too biased for estimation and disqualified it from the subsequent analyses. Model \#5 promoted an overestimation of the LA of genotype 16 by $3.5 \%$ (Figure 2C). We reanalyzed $\beta_{0}$ for this model (-1.93, $-4.05,-2.47$, and -1.38 for genotypes 4 ,
16, 18, and Morita II, respectively) and concluded that the negative $\beta_{0}$ would negative ELA even if the leaf length was zero. This biological condition is invalid, and this model was disqualified from the subsequent analyses. Model \#6 overestimated LA for genotypes 4 and 16 by $1.9 \%$ and $4.5 \%$, respectively, and nonsignificantly overestimated LA for genotype 18 and Morita II (Figure 2D). Thus, model \#6 was disqualified for the analysis of genotypes 4 and 16, but it was used to analyze genotype 18 and Morita II.

The equations that were retained for the subsequent analyses were $\# 3$, \#8, and \#9 for genotypes 4 and 16 (Figure 3) and $\# 3, \# 6$, \#8, and $\# 9$ for genotypes 18 and Morita II (Figure 4). They satisfied the requirements of lower $\mathrm{F}_{\text {calc }}$ values, higher sample-adjusted coefficients of determination, greater stability and standard errors of the estimate, and non-biased residual dispersion

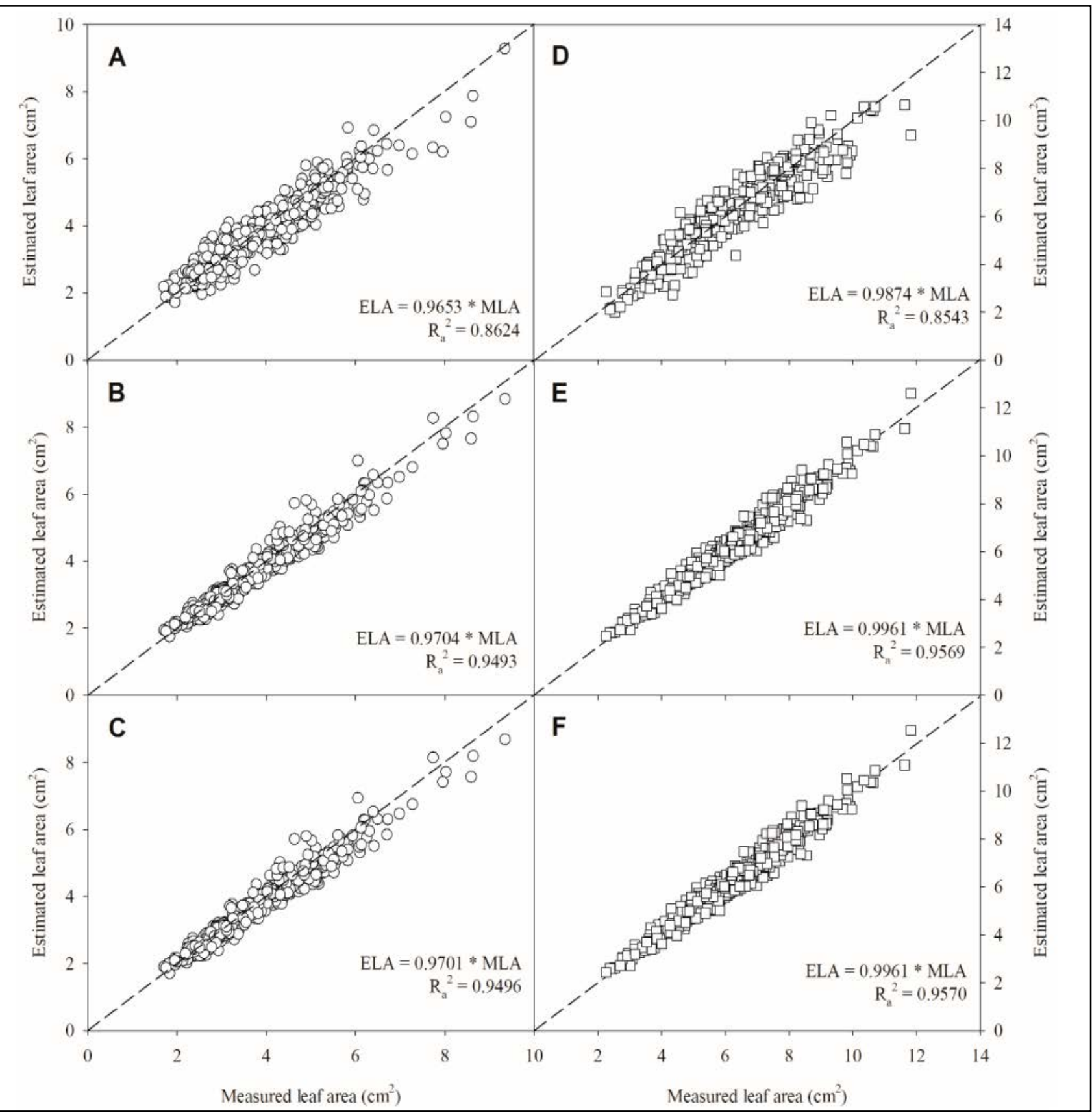

Figure 3. The relationship between estimated and measured area for the Stevia rebaudiana leaves. Leaf area was estimated in accord of equations \#3 (A, D), \#8 (B, E), and \#9 (C, F) for genotype 4 (A-C), and genotype 16 (D-F) (for more details of these equations, see Table 2). Dotted line represents the 1:1 relationship. $n=500$. Cordoba, University of Cordoba, 2020. 
patterns. Reliability and non-biased of the allometric models proposed for LA estimation were exhibited via linear regressions between the MLA and the ELA for each of them (Figures 3 and 4). Accuracy of the $\beta_{0}$ and $\beta_{1}$ coefficients increased as $\mathrm{R}_{\mathrm{a}}{ }^{2}$ approached unity. Hence, these equations could make unbiased estimates of LA for the second dataset. A careful analysis of Figures
3 and 4 showed that equations \#3, \#8, and \#9 had linear regression coefficients near 1 . Some were $>0.9960$ and $\mathrm{R}_{\mathrm{a}}{ }^{2}$ ranged from 0.8543 (Figure 3D) to 0.9976 (Figure 4C). Thus, the equations proposed here for $S$. rebaudiana LA estimation were reliable and non-biased. In contrast, equation 6 was inappropriate for $S$. rebaudiana LA estimation, as its coefficients were unstable. While the linear regression between linear measurements and MLA proposed by equation \#6 generated high linear determination coefficients (0.9904 and 0.9921 for genotypes 18 and Morita II, respectively; Table 2), the $\mathrm{R}_{\mathrm{a}}^{2}$ values of MLA versus ELA was only 0.6817 (Figure 4B), and 0.5123 (Figure 4F), respectively. Thus, LA estimates for a new population may not be the highest-

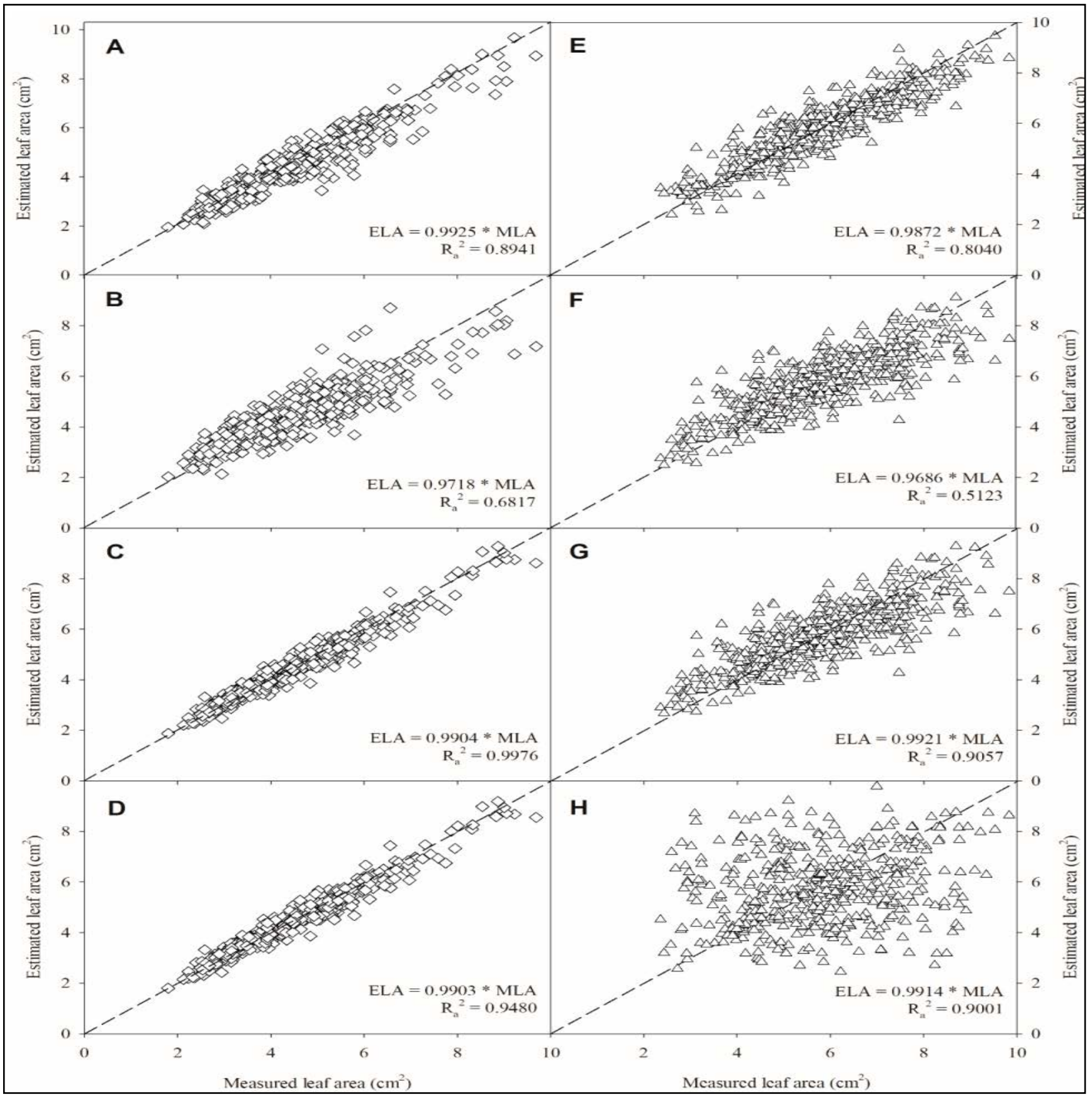

Figure 4. The relationship between estimated and measured area for the Stevia rebaudiana leaves. Leaf area was estimated in accord of equations \#3 (A, E), \#6 (B, F), \#8 (C, G), and \#9 (D, H) for genotype 18 (A-D), and Morita II (E-H) (for more details of these equations, see Table 2). Dotted line represents the 1:1 relationship. $\mathrm{n}=500$. Cordoba, University of Cordoba, 2020. 
quality ELA in the process of building allometric models. For this reason, equation \#6 was disqualified from any further $S$. rebaudiana LA estimation.

The $\beta$ 's coefficient stability in model validation was confirmed by analyzing the coefficients. $\beta_{0}$ and $\beta_{1}$ were comparatively more homogeneous in equations \#8, and \#9 but significantly more dispersed in equation \#3 (data not shown). However, equation $\# 8$ presented lower confidence intervals for both $\beta$ 's than that of equation $\#$ 9. As the $\mathrm{R}_{\mathrm{a}}{ }^{2}$ for equations \#8 and \#9 were terribly similar across all genotypes, both of the estimated $S$. rebaudiana LA were with good accuracy and without bias. Nevertheless, one objective of the present study was to develop a relatively simple, non-biased equation.
For this reason, we argued that the linear equation $\mathrm{Y}=\beta_{0}+\beta_{1}{ }^{*} \mathrm{LW}+\varepsilon_{\mathrm{i}}$ type is the best fit for $S$. rebaudiana LA estimation. Then, the statistical tests and validation of the mathematical models for $S$. rebaudiana LA estimation indicate that equation \#8 is the most suitable for this purpose.

In this study we described how simple nondestructive Stevia rebaudiana leaf measurements can accurately estimate LA. The currently used linear allometric models for estimating $S$. rebaudiana leaf area (Lima Filho \& Malavolta,1986; Ramesh et al., 2007) are inappropriate. In this study, we used 1,000 leaves per genotype to build the models and another 500 leaves per genotype to validate them while Ramesh et al. (2007) used only 80-300 leaves to construct their models. The selection based only in $\mathrm{R}^{2}$ leads to false perception of accuracy (Chatterjee \& Hadi, 2006), mainly in case of previous allometric equation (Lima Filho \& Malavolta, 1986; Ramesh et al., 2007) where the $\mathrm{R}^{2}$ ranged between 0.75 to 0.83 . Our high $\mathrm{R}_{\mathrm{a}}^{2}$ differed from those reported by Toebe et al. (2019) and Oliveira et al. (2019) for Cucurbita moschata and Pyrus communis, respectively. The LA estimate could be calculated accurately only for certain stages of leaf development, resulting in low $\mathrm{R}^{2}$, possibly a small data set. In contrast, the high $\mathrm{R}^{2}$ obtained for the estimation of the leaf area of C. moschata (Toebe et al., 2019) was derived from a very complex linear measurement of three sections per leaf. A similar analysis was

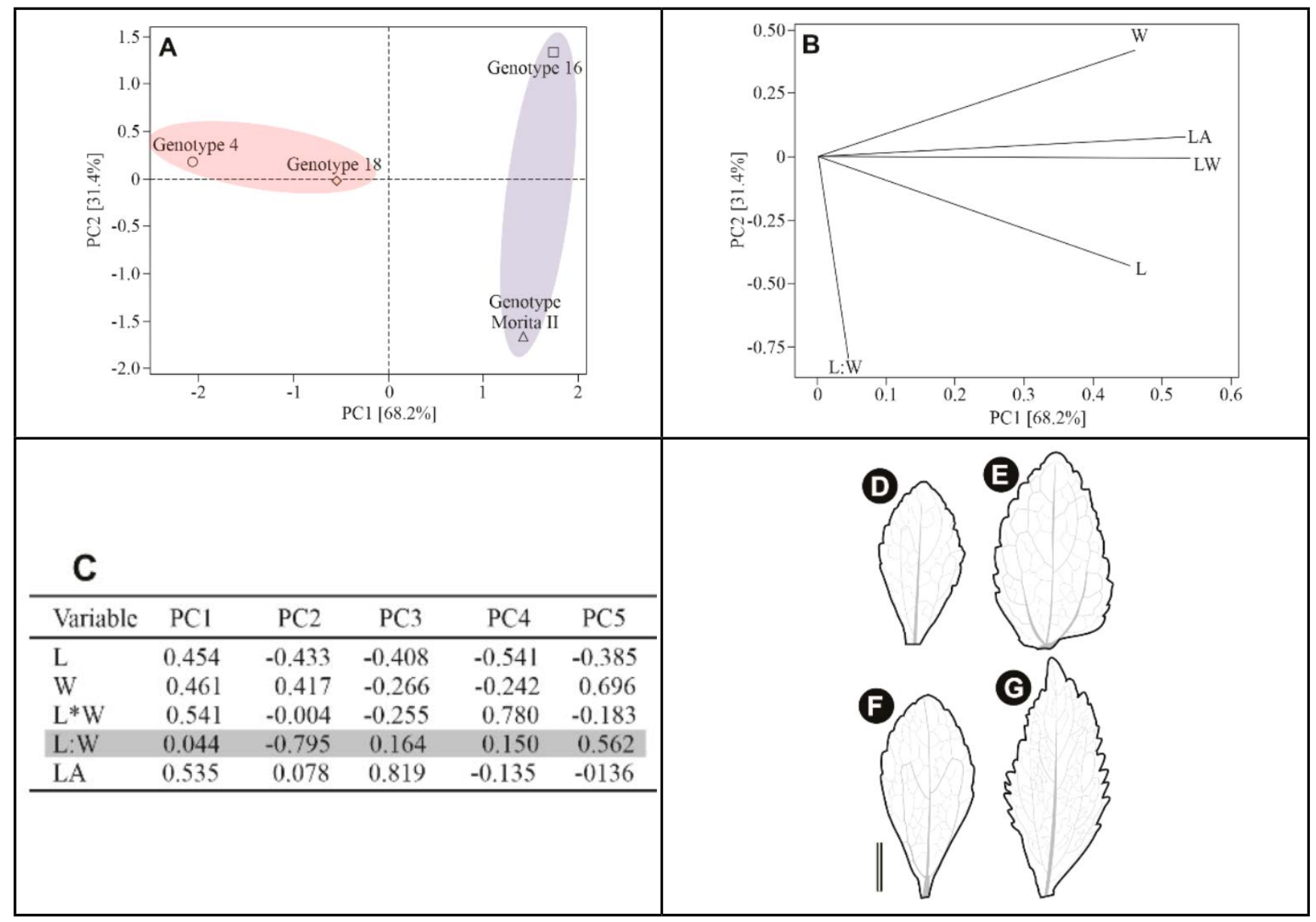

Figure 5. A. Principal component analysis (PCA) of the morphological parameters in four Stevia rebaudiana genotypes: 4, 16, 18, and Morita II. The large circles represent the two clusters formed by the Euclidean distance method considering $\sim 65 \%$ of similarity. B. Loading plot graph. In Loading plot, the direction and length of the lines are directly proportional to variables importance in separating groups. Drawings of the genotype 4 (D), 16 (E), 18 (F), and Morita II (G) of Stevia rebaudiana showing their morphotypes and leaf venation patterns. Scale for figure D-G are $1 \mathrm{~cm}$. PC1, principal component 1; PC2, principal component 2. C. The morphological parameters contributions in each principal components. L: leaf length. W: leaf width. L*W: product by leaf length and leaf width. L:W: leaf length : leaf width ratio. LA: leaf area. Cordoba, University of Cordoba, 2020. 
conducted on $P$. communis (Oliveira et al., 2019). However, none of the aforementioned studies verified residual distribution patterns or assessed $\beta$ 's stability.

In another way, an allometric equation was developed for each genotype, but this approach is neither scientifically nor agronomically practical. Thus, it was essential to generate a generalized model that could reliably estimate LA for all genotypes. An identity test and the estimated $\beta_{0}$ and $\beta_{1}$ for the equations generated for each genotype to create a generalized model encompassing all genotypes in a single sample consisted of 4,000 leaves. Only Morita II made biased estimates of a greater positive amplitude of $\beta_{0}$ and greater amplitude of $\beta_{1}$ as compared to the $\beta$ 's values produced by the generalized equation or those returned by the equations for each genotype. Thus, they could be estimated by a single equation, namely, $\mathrm{LA}=0.2798+0.6341 \mathrm{LW}+\varepsilon_{\mathrm{i}}\left[\mathrm{R}_{\mathrm{a}}{ }^{2}\right.$ $=0.9471$; RMSE (root mean square error) $=0.3947]$. However, the ANOVA (Table 3) showed that a $F_{\text {calc }}$ was 5.8fold higher than $\mathrm{F}_{\text {standard }(8 ; 3,939) \text {. For this }}$ reason, $\mathrm{H} 0$ was rejected, implying that the genotypes presented with distinct leaf morphologies could not be grouped into a single allometric model for $S$. rebaudiana LA estimation. The present study confirmed that the average leaf morphologies were distinct for the genotypes because L:W for the broader leaves of genotype 16 was smaller $(1.75 \pm 0.27)$ than that for the narrower leaves of Morita II (2.44 \pm 0.37$)$. Genotypes 4 and 18 shared similar morphological characteristics and had $L: W$ of $1.96 \pm 0.27$ and $2.03 \pm 0.22$, respectively (Figure 5A).

Power models based on leaf $\mathrm{L}$ or $\mathrm{W}$ were the most suitable for estimating LA in perennials such as coffee (Antunes et al., 2008), purging nut (Pompelli et al., 2012) and Suriname cherry (Pompelli et al., 2018). For pear (Oliveira et al., 2019) and squash (Toebe et al., 2019), however, linear models were best suited for estimating LA. We demonstrated that separate $\mathrm{L}$ and $\mathrm{W}$ each had a relatively high $\mathrm{R}_{\mathrm{a}}^{2}$ value and a narrow residual dispersion pattern. The models did not estimate $S$. rebaudiana leaf area with high precision and without bias. These limitations may invalidate these models ( Chatterjee \& Hadi, 2006). Recently, certain scholars (Oliveira et al., 2019; Toebe et al., 2019) described a best-fit equation to estimate LA for various horticultural plant species when both $\mathrm{L}$ and $\mathrm{W}$ were factored into the model. Absence of bias, homoscedastic residual scatter, and high stability of the estimated coefficients and the lack of other deficiencies were realized for the best-fit LA estimation equations applicable to any horticultural plant species whose leaves are the main organ of economic interest. Then, we proposed a model wherein $\mathrm{LA}=$ $0.2629+0.6590 * \mathrm{LW} ; \mathrm{LA}=0.1608+$ $0.6715 * \mathrm{LW} ; \mathrm{LA}=0.2957+0.5919 * \mathrm{LW}$; and $\mathrm{LA}=0.6246+0.5872 * \mathrm{LW}$ for the estimation of the LA of 4, 16, 18, and Morita II $S$. rebaudiana genotype, respectively $\left(\mathrm{R}_{\mathrm{a}}{ }^{2}=0.9431,0.9601\right.$, 0.9555, and 0.9129). The generalized model encompassing all genotypes was $\mathrm{LA}=0.2798+0.6341 * \mathrm{LW}\left(\mathrm{R}_{\mathrm{a}}{ }^{2}=0.9471\right.$; RMSE $=0.3947$ ), which accurately estimated $\sim 93 \%$ of all $S$. rebaudiana LA without bias and irrespective of genotype.

PCA attempted to cluster the genotypes and demonstrated that they could not be grouped. Figure 5A shows that Morita II and genotype 16 shared similar phylogenetic characteristics as did genotypes 4 and 18. PC1 and PC2 accounted for $99.6 \%$ and revealed that the evaluated characteristics were widely distributed. A Euclidean distance similarity of $\geq 66 \%$ indicated that genotypes 4 and 18 could not be grouped with genotypes 16 and Morita II. In the quest for the parameters rendering genotype grouping infeasible, we verified that L:W describing leaf stretching in Morita II strongly influenced $(-0.795)$ the PC2 axes as compared to the other genotypes (Figure 5C). This phenomenon was confirmed by drawing of the leaf morphotypes (Figures 5D-G), that confirms that L:W stretching made it impossible to group all genotypes or construct a generalized model for $S$. rebaudiana LA estimation. The PCA indicated wide morphological variation among S. rebaudiana leaves (Figure 5A). This phenomenon was previously addressed (Hastoy et al., 2019). Genotypes 16 and Morita II shared similar phylogenetic features as did genotypes 4 and 18 . Most of the stevia species are short day plants, meaning that after a number of long nights, the plants will flower and reduce sweetener synthesis. It has been shown that growth and sweetener production continue under long days, obtained by interruption of the long nights by RED light (Ceunen \& Geuns, 2013a). Based on this, AramendizTatis et al. (2021) describe that new $S$. rebaudiana genotypes are required to delay flowering, increase annual harvest, and augment stevioside production (Ashok et al., 2019). According to these authors, Morita II has a short vegetative phase and its first flower buds appear within a few days. In contrast, genotypes 4, 16, and 18 were selected as they have late-flowering phases and, therefore, relatively larger annual harvests. Ceunen \& Geuns (2013b) and Ceunen \& Geuns (2013a) reported that preventing flowering by interruption of the long nights by red light (e.g., by drones) is the easiest way.

Here, we developed simple predictive models to estimate the leaf areas of several $S$. rebaudiana genotypes including the globally distributed Morita II. Linear models fit $S$. rebaudiana LA better than power models. Therefore, the previously proposed LA estimation models should be avoided. Leaf morphology is similar among $S$. rebaudiana congenerics. Nevertheless, the published equations could not accurately estimate leaf area. The equations were validated by various statistical criteria and showed high coefficients of determination, coefficient stability, low sums of squares, and high simplicity. The allometric equations described herein can achieve cost-effective $S$. rebaudiana LA measurements and facilitate future research into the physiology and ecology of this agroeconomically important plant. In the present study, there were close relationships between the actual and model-predicted leaf area. A rapid and simple generalized equation was developed to predict $S$. rebaudiana leaf area, namely, $\mathrm{LA}=$ 
$0.2798+0.6341 * \mathrm{LW}\left(\mathrm{R}_{\mathrm{a}}^{2}=0.9471\right.$; RMSE $=0.3947)$. This simple model can generate results as accurate as those produced by costly apparatus and more complex estimation models. A principal component analysis disclosed that certain genotypes had features in common, whereas others did not. The methodology formulated here and the data generated may help advance $S$. rebaudiana breeding with the objectives of late flowering and increased numbers of leaves per square meter. In this way, annual yield and stevioside production may be augmented.

\section{ACKNOWLEDGEMENTS}

The authors thank the Universidad de Córdoba, Colombia for funding this research. This study was financed by the Regional Group of Participatory Research of Small Farmers of the Colombian Atlantic Coast INVEPAR, Project Manejo Agronómico de Clones de Stevia rebaudiana en el Caribe Colombiano [Grants no. FCA-02-17]. Special thanks to Drs. Luis RodríguezPaéz and Carlos Espitia-Romero for their assistance and logistical support.

\section{REFERENCES}

ACHTEN, WMJ; MAES, WH; REUBENS, B; MATHIJS, E; SINGH, VP; VERCHOT, L; MUYS, B. 2010. Biomass production and allocation in Jatropha curcas L. seedlings under different levels of drought stress. Biomass Bioenergy 34: 667-676.

ADHIKARI, R; LI, C; KALBAUGH, K; NEMALI, K. 2020. A low-cost smartphone controlled sensor based on image analysis for estimating whole-plant tissue nitrogen $(\mathrm{N})$ content in floriculture crops. Computadores e Eletronicos na Agricultura 169: 205173.

ANTUNES, WC; POMPELLI, MF; CARRETERO, DM; DAMATTA, FM. 2008. Allometric models for non-destructive leaf area estimation in coffee (Coffea arabica and Coffea canephora). Annals of Applied Biology 153: 33-40.

ARAMENDIZ-TATIS, HA; POLO, DJP; GONZÁLEZ, AIP. 2021. Caracterización morfoagronómica de 25 clones de estevia (Stevia rebaudiana Bertoni.), en condiciones del valle del Sinú medio. Revista de
Investigação Agricola e Ambiental in press.

ASHOK, K; SANATSUJAT, S; BIKRAM, S; SANJAY, K. 2019. CSIR-IHBT-ST-02 (IC0624506: INGR17053), a Stevia (Stevia rebaudiana) germplasm with delayed flowering by 120 days. Prolonged vegetate phase with more numbers of harvest per year. Indian Journal of Plant Genetic Resources 32: 260-261.

CEUNEN, S; GEUNS, JMC. 2013a. Influence of photoperiodism on the spatio-temporal accumulation of steviol glycosides in Stevia rebaudiana (Bertoni). Plant Science 198: $72-82$.

CEUNEN, S; GEUNS, JMC. 2013b. Spatiotemporal variation of the diterpene steviol in Stevia rebaudiana grown under different photoperiods. Phytochemistry 89: 32-38.

CEUNEN, S; GEUNS, JMC. 2013c. Steviol glycosides: chemical diversity, metabolism, and function. Journal of Natural Product 76: 1201-1228.

CHATTERJEE, S; HADI, AS. 2006. Regression Analysis by Example. Hoboken: John Wiley \& Sons.

CORETEAM. 2020. The R Project for Statistical Computing. Bell Laboratories. https://www.rproject.org/about.html. Accessed on April $15,2020$.

DEMIRSOY, H. 2009. Leaf area estimation in some species of fruit tree by using models as a non-destructive method. Fruits 64: 45-51.

DURBIN, J; WATSON, GS. 1950. Testing for serial correlation in least squares regression I. Biometrika 37: 409-428.

GUERRERO, AB; EMETERIO, LS; DOMEÑO, I; IRIGOYEN, I; MURO, J. 2018. Steviol glycoside content dynamics during the growth cycle of Stevia rebaudiana Bert. American Journl of Plant Science 9: 892-901.

HASTOY, C; COSSON, P; CAVAIGNAC, S; BOUTIÉ, P; WAFFO-TEGUO, P; ROLIN, D; SCHURDI-LEVRAUD, V. 2019. Deciphering performances of fifteen genotypes of Stevia rebaudiana in southwestern France through dry biomass and steviol glycoside evaluation. Indian Crop Production 128: 607-619.

KINGHORN, AD; SOEJARTO, DD. 1991. Stevioside. In: NABORS, LO; GELARDI, $\mathrm{RC}$ (eds). Alternative Sweeteners, $2^{\text {nd }}$ editions, revised and expanded. New York: Academic Press, p.157-171.

LIMA FILHO, OP; MALAVOLTA, E. 1986. Estimativa de área foliar em estevia (Stevia rebaudiana (Bert.) Bertoni). Unipi. http://www. Ini.unipi.it/stevia/stevia/estimativadearea.htm. Accessed May 17, 2020.

LOZANO-ISLA, F; ALFARO, OB; SANTANA, DG; RANAL, MA; POMPELLI, MF. 2020. Germination indexes for seed germination variables for ecophysiological studies [R package GerminaR version 1.4.2]. $\mathrm{R}$ Development Core Team 2020, Federal University of Pernambuco.

OLIVEIRA, VS; SANTOS, KTH; MORAIS, AL; SANTOS, GP; SANTOS, JSH;
SCHMILDT, O; CZEPAK, MP; GONTIJO, I; ALEXANDRE, RS; SCHMILDT, ER. 2019. Non-destructive method for estimating the leaf area of pear cv. 'Triunfo'. Journal of Agricultural Science 11: 14-21.

PANDEY, SK. 2011. A simple, cost-effective method for leaf area estimation. Journal of Botany 2011: 658240.

POMPELLI, MF; ANTUNES, WC; FERREIRA, DTRG; CAVALCANTE, PPGS; WANDERLEY-FILHO, HCL; ENDRES, L. 2012. Allometric models for non-destructive leaf area estimation of the Jatropha curcas. Biomass Bioenergy 36: 77-85.

POMPELLI, MF; MENDES, KR; RAMOS, MV; SANTOS, JNB; YOUSSEF, DTA; PEREIRA, JD; ENDRES, L; JARMA-OROZCO, A; GOMES, RS; JARMA-ARROYO, B; SILVA, ALJ; SANTOS, MA; ANTUNES, WC. 2019. Mesophyll thickness and sclerophylly among Calotropis procera morphotypes reveal watersaved adaptation to environments. Journal of Arid Land 11: 795-810.

PUTNIK, P; BEZUK, I; BARBA, FJ; LORENZO, JM; POLUNIĆ, I; BURSAĆ, DK. 2020. Sugar reduction: Stevia rebaudiana Bertoni as a natural sweetener. In: BARBA, FJ; PUTNIK, P; KOVAČEVIĆ, DB (eds). Agri-Food Industry Strategies for Healthy Diets and Sustainability. San Diego: Academic Press, p.123-152.

RAMESH, K; RAMAWAT, N; SINGH, V. 2007. Leaf area distribution pattern and nondestructive estimation methods of leaf area for Stevia rebaudiana (Bert.) Bertoni. Asian Journal of Plant Science 6: 1037-1043.

TEOBALDELLI, M; ROUPHAEL, Y; GONNELLA, M; BUTTARO, D; RIVERA, CM; MUGANU, M; COLLA, G; BASILE, B. 2020. Developing a fast and accurate model to estimate allometrically the total shoot leaf area in grapevines. Scientia Horticulturae 259: 108794 .

TOEBE, M; SOUZA, RR; MELLO, AC; MELO, PJ; SEGATTO, A; CASTANHA, AC. 2019. Leaf area estimation of squash 'Brasileirinha' by leaf dimensions. Ciência Rural 49: e20180932.

TOTTÉ, N; CHARON, L; ROHMER, M; COMPERNOLLE, F; BABOEUF, I; GEUNS, JMC. 2000. Biosynthesis of the diterpenoid steviol, an ent-kaurene derivative from Stevia rebaudiana Bertoni, via the methylerythritol phosphate pathway. Tetrahedron Letters 41: 6407-6410.

WALTHER, BA; MOORE, JL. 2005. The concepts of bias, precision and accuracy, and their use in testing the performance of species richness estimators, with a literature review of estimator performance. Ecography 28: 815-829.

ZUUR, AF; ELENA, NI; ELPHICK, CS. 2009. A protocol for data exploration to avoid common statistical problems. Method Ecol Evolution 1: 3-14. 